\title{
Changes in CsFT Transcript Abundance at the Onset of Low-temperature Floral Induction in Sweet Orange
}

\author{
Eduardo J. Chica ${ }^{1}$ and L. Gene Albrigo ${ }^{2}$ \\ Citrus Research and Education Center, University of Florida, IFAS, 700 Experiment Station Road, \\ Lake Alfred, FL 33850
}

\begin{abstract}
AdDitional INDEX words. citrus, flowering, photoperiod, light, circadian clock
Abstract. As in arabidopsis (Arabidopsis thaliana), putative citrus (Citrus) Flowering locus T (FT) homologs are strong promoters of flowering and apparently are key components of the molecular mechanism controlling floral induction in these species. An abundance of citrus FT gene transcripts during floral induction is consistent with the role of their products as floral-promoting signals. However, specific details about how the floral induction process is initiated and sustained remain largely unknown. We report changes in transcript abundance of a $F T$ gene $(C s F T)$ from sweet orange (Citrus sinensis) at the onset of floral induction by low temperatures and at different times of the day. Using a combination of field and growth room experiments, we determined that the abundance of $C s F T$ transcripts increased within 1 day after initial exposure to cool floral-inductive temperatures, and that $C s F T$ transcript abundance was higher in the afternoon than in the morning and evening. The presence of photoperiod cycles seemed to be required to sustain the increasing $C s F T$ transcript abundance, because exposure to floral inductive conditions under continuous light or darkness did not increase the abundance of $C s F T$ transcripts after 3 days. Our results suggest that the regulation of $C s F T$ expression responds rapidly (overnight) to the onset of floralinductive cool temperatures, is sensitive to changes in temperature, and requires alternation of light and dark cycles to sustain transcript accumulation during induction.
\end{abstract}

In arabidopsis, the protein encoded by the gene Flowering locus $T$ is a potent mobile flowering signal (Corbesier et al., 2007). FT is produced in the phloem of leaves and transported to shoot apical meristems where, along with bZIP protein FD, it activates the expression of floral identity genes that initiate floral organ morphogenesis (Abe et al., 2005; An et al., 2004; Mathieu et al., 2007; Michaels et al., 2005; Wigge et al., 2005). Up-regulation of $F T$ expression is key for the induction of flowering in arabidopsis by long-day photoperiods in a mechanism that involves integration of light signals and the circadian clock of the plant (Suárez-Lopez et al., 2001; Valverde et al., 2004; Yanovsky and Kay, 2002). In arabidopsis, FT is also a point of integration of floral-promoting and -inhibiting signals initiated by vernalization, gibberellins, and plant developmental signals (Samach et al., 2000).

In citrus, floral induction is generally considered to be insensitive to photoperiod with no differences in the number of inflorescences formed under 8-, 12-, or 16-h days (Moss, 1969). The only two known factors capable of inducing flowering in citrus are temperatures less than $20^{\circ} \mathrm{C}$ and water deficit (Cassin et al., 1969; Moss, 1969). Interestingly, despite the differences in the environmental stimuli inducing flowering in citrus and arabidopsis, putative $F T$ genes have been found in several Citrus species (Chica and Albrigo, 2013; Muñoz Fambuena et al., 2012a; Nishikawa et al., 2007, 2009; Shalom et al., 2012). In 'Satsuma' mandarin (Citrus unshiu), three FT genes have been identified (CiFT, CiFT2, and CiFT3), of which CiFT3 expression was better correlated to floral-inductive conditions (Nishikawa et al., 2007). However, the exact evolutionary relationships

Received for publication 14 Feb. 2013. Accepted for publication 22 Mar. 2013. ${ }^{1}$ Current address: Carrera de Ingeniería Agrícola y Biológica, Escuela Superior Politécnica del Litoral, Km. 30.5 vía perimentral, Guayaquil, Ecuador.

${ }^{2}$ Corresponding author. E-mail: albrigo@ufl.edu. between the $F T$ genes in citrus remain unresolved. Results from mutant complementation and overexpression experiments in citrus and other species support the role of citrus $F T$ genes as potent flowering promoters (Endo et al., 2005; Kobayashi et al., 1999; Matsuda et al., 2009; Nishikawa et al., 2009). Furthermore, the patterns of expression of citrus $F T$ genes are consistent with their hypothetical role as providing flowering signals generated in response to floral induction (Chica and Albrigo, 2013; Muñoz Fambuena et al., 2011, 2012a, 2012b; Nishikawa et al., 2007, 2009). The up-regulation of FT expression by different factors in citrus than in arabidopsis suggests adaptation of the mechanism regulating FT expression to different environmental stimuli, perhaps as a result of the perennial nature and habitat of citrus compared with arabidopsis. However, exactly how these mechanisms might differ in citrus and arabidopsis has not been determined. Two key aspects of the regulation of $F T$ in arabidopsis are light and circadian clock control during the initial exposure to floralinductive long days (Suárez-Lopez et al., 2001; Valverde et al., 2004; Yanovsky and Kay, 2002). Although the involvement of putative $F T$ homologs in citrus floral induction is evident, details about the fine regulation remain unknown.

The objectives of this work were to determine the sensitivity of the $C s F T$ gene to floral-inductive signals, primarily from cool temperatures applied in various ways, and to characterize the changes in $C s F T$ transcript abundance at the beginning of floral induction. We also investigated whether the expression of $C s F T$ changed during the day like in arabidopsis and whether dark/light had any input on the regulation of CsFT expression.

\section{Materials and Methods}

Plant material. Potted trees of 'Washington Navel' sweet orange from rooted cuttings ( 2 to 3 years old, $\approx 1 \mathrm{~m}$ tall growing 
in 12-L pots) were used in these experiments. Trees had fully mature foliage (no tender shoots). Before the experiments, the trees were kept in a greenhouse located at the University of Florida Citrus Research and Education Center in Lake Alfred (lat. $28^{\circ} 5^{\prime} \mathrm{N}$, long. $81^{\circ} 43^{\prime} \mathrm{W}$ ). Minimum and maximum temperature were 23 and $31^{\circ} \mathrm{C}$, respectively, and trees were watered to saturation every $2 \mathrm{~d}$. Trees in the greenhouse were exposed to natural variations in photoperiod during the period preceding the experiments during Summer and Fall 2010 (decreasing from $12.5 / 11.5$ to $11 / 13^{\circ} \mathrm{C} \mathrm{h}$, day/night). Photosynthetic photon flux density ranged between 1210 and $1340 \mu \mathrm{mol} \cdot \mathrm{m}^{-2} \cdot \mathrm{s}^{-1}$, whereas trees were in the greenhouse before the experiments.

In one field experiment, we used 15-year-old 'Valencia' sweet orange trees grafted on 'Carrizo' citrange $(C$. sinensis $\times$ Poncirus trifoliata) rootstock growing in an orchard at the University of Florida Citrus Research and Education Center in Lake Alfred. Trees in this orchard received irrigation, fertilization, and pest/disease management like in neighboring commercial groves.

Diurnal Changes in TRANSCRIPT ABUndance. To investigate changes in CSFT transcript abundance during the day, potted trees were transferred from the greenhouse to growth rooms at a constant temperature of either $12{ }^{\circ} \mathrm{C}$ (floral-inductive) or $23{ }^{\circ} \mathrm{C}$ (non-floral-inductive) with a $11 / 13$-h photoperiod. Trees were kept under these conditions for $15 \mathrm{~d}$ and then leaves were sampled every $2 \mathrm{~h}$ from 0600 to $1800 \mathrm{HR}$ for $2 \mathrm{~d}$ (consecutive). A similar experiment was conducted using field-grown trees during July (Summer) and Dec. (Winter) 2010. In the field experiment, samples were collected at 0800, 1500, 1800, and 2100 HR for $2 \mathrm{~d}$ (consecutive). During summer, CsFT transcript accumulation was evaluated in well-irrigated trees and trees that had received no irrigation for $60 \mathrm{~d}$. Trees sampled during winter were kept well irrigated at all times. Each experiment was analyzed separately using a repeated measurements model with three tree replicates (at least six leaves sampled per tree).

INITIAL CHANGES IN TRANSCRIPT ABUNDANCE AT THE ONSET OF FLORAL INDUCTION. To investigate the initial changes in the abundance of $C s F T$ transcripts at the onset of induction, three experiments were conducted. In the first experiment, potted trees kept at $23{ }^{\circ} \mathrm{C}$ were transferred to a growth room at $12{ }^{\circ} \mathrm{C}$ either at 0700 or $1500 \mathrm{HR}$. CsFT transcript abundance was measured at the time of the transfer, $2 \mathrm{~h}$ after the transfer, and at 0700 or $1500 \mathrm{HR}$ on the day after the transfer to evaluate the kinetics of CSFT transcript accumulation at the onset of inductive conditions. Data were analyzed using a repeated measurements model with three-tree replicates. In the second experiment, potted trees were transferred from $23{ }^{\circ} \mathrm{C}$ to growth rooms at $5,10,15,20$, or $23{ }^{\circ} \mathrm{C}$ for $3 \mathrm{~d}$ and $C s F T$ transcript abundance was measured right before and $3 \mathrm{~d}$ after the transfer to evaluate the sensitivity of $C s F T$ to temperature. Data were analyzed using analysis of variance (ANOVA) and a general linear model with three tree replicates. In the third experiment, abundance of CsFT transcripts was determined in leaves of mature field-grown trees $2 \mathrm{~d}$ before, during, and after the passing of a cold front that reduced night temperatures below the floral induction threshold of $20{ }^{\circ} \mathrm{C}$ (Valiente and Albrigo, 2004) for the first time in the floral induction season (2010-11). Weather forecasting was monitored periodically to anticipate the onset of inductive temperatures. Samples were collected at 0800 and 1500 HR. Data were analyzed using a repeated measurements model with four tree replicates. ANOVA was used to compare CsFT transcript abundance before and after the cold front.
INFLUENCE OF LIGHT/DARK CYCLES ON TRANSCRIPT ABUNDANCE. To investigate whether light/dark cycles were required to sustain increasing levels of $C s F T$ transcript abundance, trees kept at $23{ }^{\circ} \mathrm{C}$ and $11 / 13$-h photoperiod were transferred to rooms at $12{ }^{\circ} \mathrm{C}$ and $0 / 24-\mathrm{h}$ (constant darkness), 24/0-h (constant light), or 11/13-h photoperiods. CsFT transcript abundance was measured in leaves before and $3 \mathrm{~d}$ after the transfer. The experiment was conducted using a completely randomized design. Data were analyzed using ANOVA with three tree replicates per treatment.

Sample Collection and RNA extraction. In all the experiments, only leaves were sampled. Samples consisted of a pool of six leaves per tree replicate. Only mature healthy fully expanded leaves located at the three most distal position of sixto seven-node-long, 4- to 12-month-old shoots were used for the experiments. When time of the day is not specified, samples were collected between 1445 and 1515 HR local standard time (UTC-5). After collection, samples were immediately frozen in liquid nitrogen and stored at $-80^{\circ} \mathrm{C}$ until used.

Total RNA was extracted from the samples using a phenolchloroform precipitation method (Chomczynski and Sacchi, 1987) and purified using silica membranes (Epoch Biolabs, Sugar Land, TX) with on-column DNase digestion (Qiagen, Germantown, MD). RNA quality was evaluated by spectrophotometry and denaturing gel electrophoresis and quantified by spectrophotometry (Sambrook et al., 1989).

QUANTITATIVE REVERSE TRANSCRIPTION-POLYMERASE CHAIN REACTION. Five hundred nanograms of total RNA were used for cDNA synthesis in a $20-\mu \mathrm{L}$ reaction with oligo dT primers (SuperScriptIII ${ }^{\circledR}$; Invitrogen, Carlsbad, CA). One microliter of the synthesized cDNA was used for two-step $\left(95^{\circ} \mathrm{C}\right.$ denaturation and $60^{\circ} \mathrm{C}$ for $1 \mathrm{~min}$ annealing and extension) quantitative polymerase chain reaction (qPCR) in a $20-\mu \mathrm{L}$ reaction using SYBR green detection $\left(\right.$ SYBR $^{\circledR}$ Premix ExTaqTMII; Takara, Mountain View, CA) on a Applied Biosystems 7500 FAST real-time PCR system (Life Technologies, Carlsbad, CA). The primers used to amplify $C s F T$ were: $5^{\prime}$-CGGCGGAAGGACT ATGAC-3' and 5'-TGTGAGAAAGCCAGAGAGGAA-3', which were designed based on the sequence of $C i F T 3$ reported by Nishikawa et al. (2007). The CiFT3 sequence was selected over CiFT2 or CiFT because, reportedly, CiFT3 correlated better to floral-inductive treatments (Nishikawa et al., 2007). The reference gene used for relative quantification of $C s F T$ abundance was glyceraldehyde 3-phosphate dehydrogenase $(C s G A P D H)$. CsGAPDH was amplified using the following primers: 5' -GGAAGGTCAAGATCGCAATCAA-3' and 5' CGTCCCTCTGCAAGATGACTCT- $3^{\prime}$. The qPCR assay for CsFT was validated for specific amplification and optimized for amplification efficiencies between 1.85 and 1.99 with a linear dynamic range of $6 \log 10$. Relative gene expression was calculated as a fold change ratio using Pfaffl's method (Pfaffl, 2001) with sliding-window efficiencies calculated for each reaction using the sliwin function in the qpcR $R$ package (Ritz and Spiess, 2008).

Statistical analysis. Statistically significant differences were determined at $P \leq 0.05$. All statistical analyses were executed in R (R Development Core Team, 2011).

\section{Results}

Changes in $\boldsymbol{C S F}$ T transcript abundance during the day. Abundance of CsFT transcripts was consistently higher in the 
afternoon than in the morning and evening in the three experiments conducted in the growth room or field regardless of exposure to floral-inductive conditions (Fig. 1). In the growth rooms, $C s F T$ transcripts were at higher levels in trees kept at $12{ }^{\circ} \mathrm{C}$ than at $23^{\circ} \mathrm{C}$, but this difference was smaller in the morning and evening than in the afternoon. CsFT transcript abundance was highest between 1200 and $1500 \mathrm{HR}$. Under field conditions in the summer, no significant differences in $C s F T$ transcript abundance were detected between well-irrigated trees and trees under water deficit by repeated measurement ANOVA. However, significant differences $(t$ test $P \leq 0.05$ ) were detected comparing the abundance of CsFT transcripts at 1500 and 1800 HR with higher abundance in trees under water deficit than in well-irrigated trees at these times.

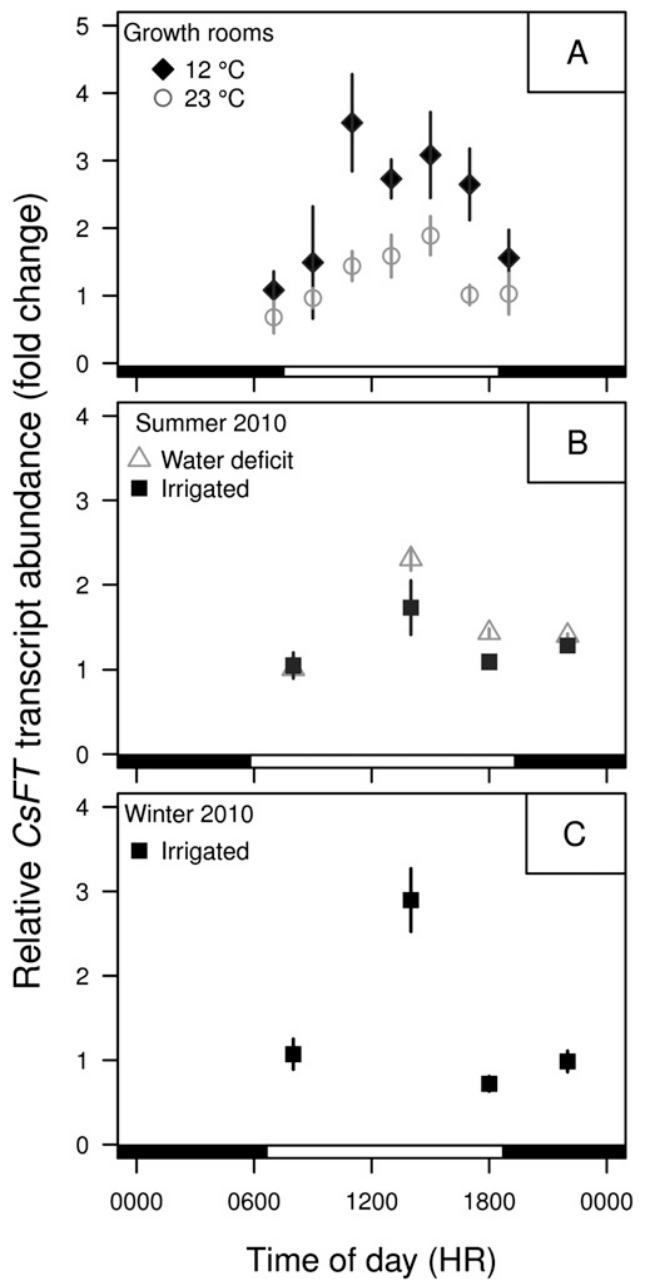

Fig. 1. Changes in CsFT transcript abundance in sweet orange leaves during the day under different environmental conditions. Each panel represents an independent experiment. (A) Potted sweet orange trees in growth rooms at 12 and $23{ }^{\circ} \mathrm{C}$ for $15 \mathrm{~d}$. (B) Mature field-grown sweet orange trees under irrigation or water deficit in July (Summer 2010). (C) Mature field-grown sweet orange trees under irrigation in December (Winter 2010). Data are means of $2 \mathrm{~d}$ (consecutive) \pm SE (three tree replicates sampled at each time point each day). In all three experiments, significant differences $(P \leq 0.05)$ associated with time of the day were detected by repeated measurement analysis of variance (ANOVA). In the growth rooms, significant differences were also detected between trees kept at 12 and $23^{\circ} \mathrm{C}$. In Summer 2010, no significant differences were detected between irrigated trees and trees under water deficit. Black and white rectangles at the bottom of the graphs indicate the photoperiod in each experiment.
INITIAL CHANGES IN CSFT TRANSCRIPT ABUNDANCE DURING FLORAL INDUCTION. Transfer from non-floral-inductive to floralinductive temperatures resulted in $\mathrm{a} \approx 1.5$ - to -2 fold increase in CsFT transcript abundance $24 \mathrm{~h}$ after transfer (Fig. 2). No differences in the levels of $C s F T$ transcript abundance were detected after one night of treatment between trees that were transferred at 0700 or $1500 \mathrm{HR}$ on Day 1. CsFT transcript abundance on trees transferred to inductive conditions at $0700 \mathrm{HR}$ was similar to the pre-transfer levels of the trees transferred at 1500 HR; no differences were detected between these groups at $1700 \mathrm{HR}$. A similar response was also observed in field-grown trees after night temperatures below $20{ }^{\circ} \mathrm{C}$ (Fig. 3). After a single night below $20^{\circ} \mathrm{C}, C s F T$ transcript abundance at 0800 and $1500 \mathrm{HR}$ increased $\approx 1.5$ to two times relative to the levels observed on the two previous days. After a second night below $20{ }^{\circ} \mathrm{C}, C s F T$ transcript abundance increased further, but the magnitude of this increase was greater at 1500 than at $0800 \mathrm{HR}$.

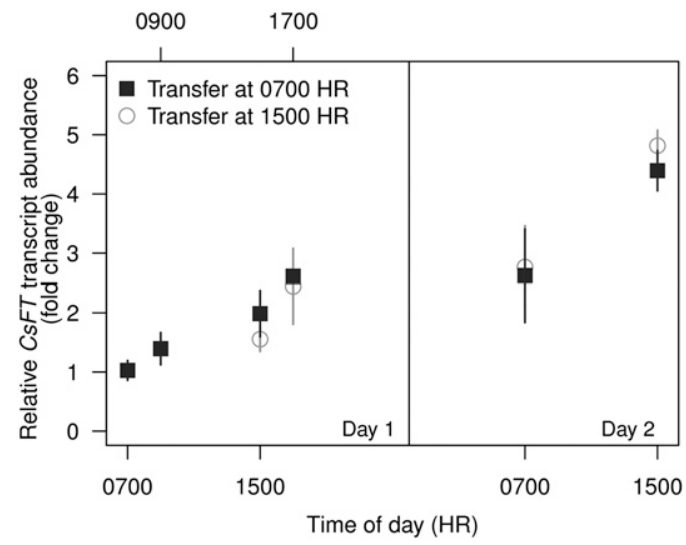

Fig. 2. Changes in $C s F T$ transcript abundance in leaves of potted sweet orange trees after transfer from non-floral-inductive $\left(23^{\circ} \mathrm{C}\right)$ to floral-inductive $\left(12^{\circ} \mathrm{C}\right)$ temperatures in the morning $(0700 \mathrm{HR})$ or in the afternoon $(1500 \mathrm{HR})$. Data are means $\pm \mathrm{SE}(\mathrm{n}=3)$. No significant differences $[P \leq 0.05$, repeated measurement analysis of variance (ANOVA) ] were detected between trees transferred at 0700 or $1500 \mathrm{HR}$. Time had a significant effect on transcript abundance.

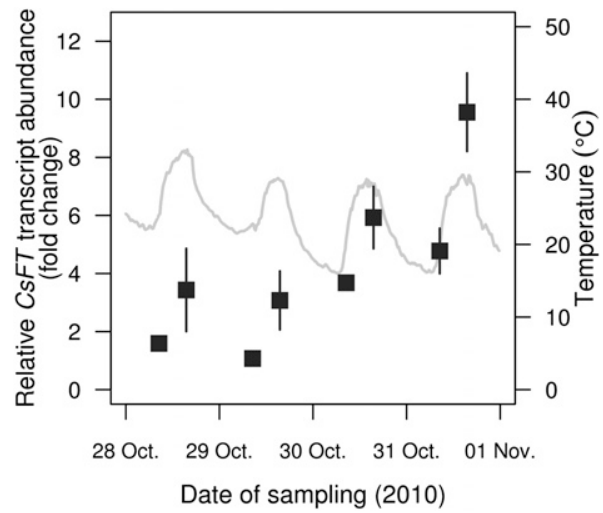

Fig. 3. Changes in CsFT transcript abundance in leaves of mature field-grown 'Valencia' sweet orange trees as influenced by the first natural drop in ambient temperature below $20^{\circ} \mathrm{C}$ of the $2010-11$ floral induction season. Trees were sampled at 0800 and $1500 \mathrm{HR} 2 \mathrm{~d}$ before and after the passing of the front. Transcript data (black squares) are means $\pm \mathrm{SE}(\mathrm{n}=3)$. Significant differences $(P \leq 0.05)$ between samples collected before and after the temperature drop (i.e., 28 to 29 Oct. vs. 30 to 31 Oct.) and between 0800 and 1500 HR were detected by analysis of variance (ANOVA). The gray line shows the change in temperature during the period. 
Day temperatures remained above $20{ }^{\circ} \mathrm{C}$ at all times. In the growth rooms, transfer of potted trees to different inductive temperatures produced different $C s F T$ transcript levels of abundance in leaves with the highest abundance of CsFT transcripts observed in trees transferred to $15^{\circ} \mathrm{C}$ for $3 \mathrm{~d}$ compared with the other temperatures (Fig. 4).

DEPENDENCE ON LIGHT/DARK CYCLES TO SUSTAIN INCREASING LEVELS OF CSFT TRANSCRIPT ABUNDANCE. Alternation of periods of darkness and light were required to allow $C s F T$ transcript abundance to increase after $3 \mathrm{~d}$ at floral-inductive temperatures. No statistically significant differences were detected between pre-transfer levels and levels of CsFT transcripts after $3 \mathrm{~d}$ of floral induction temperatures in trees kept either under constant darkness or constant light, whereas the level of CsFT transcript abundance after $3 \mathrm{~d}$ of floral induction in trees kept under a $11 / 13$ h-photoperiod was $\approx 3.5$ times higher than pre-transfer levels (Fig. 5).

\section{Discussion}

Several putative homologs of arabidopsis floral-promoting and floral identity genes have been isolated in citrus during the

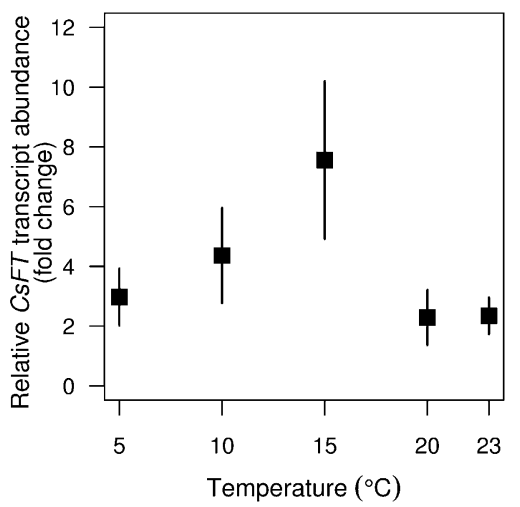

Fig. 4. CsFT transcript abundance in sweet orange leaves $3 \mathrm{~d}$ after transfer from $23{ }^{\circ} \mathrm{C}$ to different temperatures. Data are means \pm SE $(n=3)$. The effect of temperature was statistically significant $[P \leq 0.05$, analysis of variance (ANOVA)].

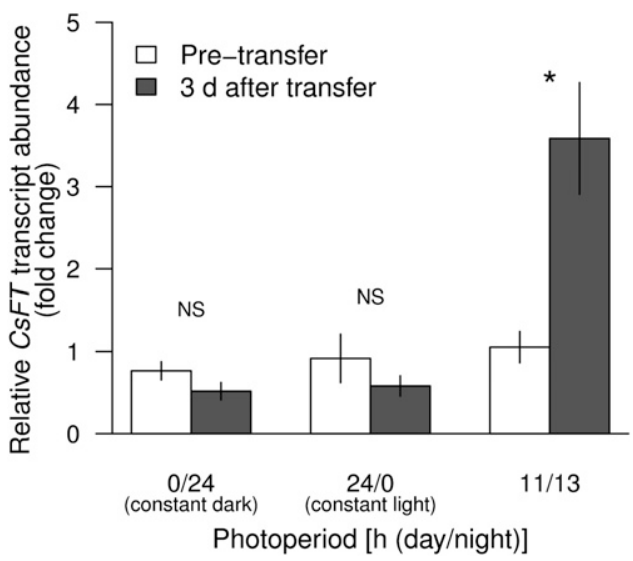

Fig. 5. CsFT transcript abundance in sweet orange leaves $3 \mathrm{~d}$ after transfer from $23{ }^{\circ} \mathrm{C}$ to floral-inductive temperature $\left(12{ }^{\circ} \mathrm{C}\right)$ under daily constant illumination, darkness or alternating light and dark. Data are means $\pm \mathrm{SE}(\mathrm{n}=3)$. NS indicates that differences between pre- and post-transfer CsFT abundance were non-significant whereas the asterisk indicates that statistically significant differences were detected $(P \leq 0.05)$. last decade (Li et al., 2010; Nishikawa et al., 2007; Pillitteri et al., 2004a, 2004b; Tan and Swain, 2007; Zhang et al., 2009). Mutant complementation analysis and patterns of expression support the conservation of the function of these genes in citrus and arabidopsis. Among these genes, the citrus FT genes have been widely investigated (Endo et al., 2005, 2009; Kobayashi et al., 1999; Matsuda et al., 2009; Muñoz Fambuena et al., 2012a; Nishikawa et al., 2007, 2009, 2010) because of the potential conservation of $F T$ function as a mobile floral-promoting signal in arabidopsis (Corbesier et al., 2007; Tamaki et al., 2007). Interestingly, whereas in arabidopsis, long days induce the expression of FT (Samach et al., 2000), in citrus, flowering has been considered practically photoperiod-insensitive (Moss, 1969), yet overexpression of citrus FT genes in arabidopsis, sweet orange, trifoliate orange (Poncirus trifoliata), and pear (Pyrus communis) promotes early flowering (Endo et al., 2005; Kobayashi et al., 1999; Matsuda et al., 2009; Rodríguez et al., 2012). Furthermore, patterns of expression of FT genes in citrus are consistent with its up-regulation by floral-promoting stimuli (Chica and Albrigo, 2013; Endo et al., 2005; Muñoz Fambuena et al., 2012a, 2012b; Nishikawa et al., 2007, 2009), suggesting that the mechanisms inducing FT expression in citrus could have evolved to respond to stimuli other than photoperiod. In this work we determined changes in the abundance of CsFT transcripts early during induction as well as in response to extreme photoperiods and at different times of the day to gain insight regarding differences in the mechanisms regulating floral induction in citrus and arabidopsis.

First, we investigated whether the abundance of CsFT transcripts changed during the day. In arabidopsis, induction of flowering by long days depends on the integration of light and clock signals by Constans $(C O)$. The expression of $C O$ is regulated by the activity of genes related to the circadian clock (Suárez-Lopez et al., 2001). CO expression peaks between 12 and $16 \mathrm{~h}$ after dawn; however, the protein encoded by this gene is unstable in the dark and targeted for degradation in the proteasome if light is not present (Valverde et al., 2004). Under long days, the highest level of $C O$ expression coincides with light conditions resulting in the stabilization of the protein encoded by $C O$, which activates $F T$ expression and ultimately results in floral induction (Corbesier et al., 2007; Valverde et al., 2004). In sweet orange, the CsFT transcript abundance changed consistently during the day in the same way under varied conditions with highest levels measured in the afternoon hours [6 to $11 \mathrm{~h}$ after dawn (Fig. 1)]. Under growth room conditions, abundance of CsFT transcripts was reduced after 1500 HR (Fig. 1A) when trees were still illuminated. Together, these results suggest that there could be a mechanism integrating information from the circadian clock of the tree and CsFT transcription like in arabidopsis. The length of the period at which accumulation of $C s F T$ transcript was most abundant could explain the perceived insensitivity of citrus flowering to photoperiod. In arabidopsis, $F T$ transcripts accumulate to the highest levels $16 \mathrm{~h}$ after dawn, whereas we recorded the highest accumulation of CsFT transcripts only $6 \mathrm{~h}$ after dawn (Corbesier et al., 2007). In the experiments that tested the sensitivity of sweet orange flowering to photoperiod (Moss, 1969), the shortest day length evaluated was $8 \mathrm{~h}$. Thus, assuming that the product of $C s F T$ is a floral-promoting signal, flowering could still have been induced because $C s F T$ transcripts could have accumulated to a high level under these relatively short days. In addition, rather than citrus flowering being photoperiod-insensitive, 
citrus could have a relaxed photoperiod requirement that instead of having a floral-promoting effect could have a floralallowing effect. The changes in CsFT transcript abundance during the day was observed not only under floral-inductive conditions, but also under non-floral-inductive conditions (Fig. 1), suggesting that the hypothetical mechanism regulating flowering through $C s F T$ is not activated but promoted. CsFT transcripts were two times more abundant in the afternoon than in the morning.

In our second set of experiments, we characterized the first changes in $C s F T$ transcript abundance induced by the transfer from non-floral-inductive to floral-inductive conditions. Following our results from the experiment describing the changes in $C s F T$ transcript abundance during the day, we investigated whether transferring trees to floral-inductive temperatures in the morning could increase the abundance of $C s F T$ transcripts in the afternoon because of the prolonged exposure to the floral stimuli. We found no differences at $1500 \mathrm{HR}$ between trees transferred to floral-inductive temperatures in the morning and trees kept at non-floral-inductive temperatures until $1500 \mathrm{HR}$ (Fig. 2). Thus, the additional exposure to the floral stimuli during the morning and early afternoon did not increase $C s F T$ transcript abundance beyond the natural diurnal change. On the second day of induction, no differences in $C s F T$ transcript abundance were detected between trees transferred to floralinductive temperatures either at $0700 \mathrm{HR}$ or $1500 \mathrm{HR}$ on the previous day (i.e., after 24 and $16 \mathrm{~h}$ of exposure to the floral stimuli), suggesting that exposure to floral-inductive conditions during the afternoon and night could be more effective in promoting an increase in $C s F T$ transcript accumulation than exposure during the morning. Results from this experiment and the experiment using field-grown trees (Fig. 3) show that exposure to floral-inductive temperatures for one night was enough to increase the abundance of $C s F T$ transcripts in the morning to the levels observed in the afternoon of the previous day. Our results suggest that up-regulation of $C s F T$ expression responds within hours to the onset of floral-inductive temperatures when the change in temperature occurs during the afternoon or overnight. This is similar to how FT expression is up-regulated in arabidopsis after exposure to a single floralinductive long day (Corbesier et al., 2007). In arabidopsis, a single exposure to greater than 12-h daylength was enough to induce flowering (Corbesier et al., 1996). In citrus, significant floral induction required more than 2 weeks (Moss, 1969) but given that a single day exposure caused measurable upregulation of $C s F T$, the minimum time requirement for floral induction in citrus may be less than 2 weeks.

In sweet orange, the intensity of floral induction is not only a quantitative process that depends on the time of exposure, but also a qualitative process that depends on the level at which the environmental floral inductive stimuli is present (Moss, 1969; Southwick and Davenport, 1986). Flowering in citrus is not induced above $20^{\circ} \mathrm{C}$ (Moss, 1969; Valiente and Albrigo, 2004) with lower temperatures being more effective for floral induction. Between 10 and $15{ }^{\circ} \mathrm{C}$ is considered optimum for induction (Moss, 1969) and below $5^{\circ} \mathrm{C}$ is non-inductive (GarcíaLuís and Kandušer, 1995). The abundance levels of CsFT transcripts at different temperatures in Figure 4 correspond to the levels of floral induction achieved at different temperatures reported in the literature with the highest abundance at $15^{\circ} \mathrm{C}$ (García-Luís and Kandušer, 1995; Moss, 1969). Thus, if CsFT transcripts need to accumulate to a certain level to effectively induce flowering in citrus, the time required to achieve this level could be a function of the temperature of induction.

In our last experiment, we re-visited the photoperiod requirement of sweet orange flowering by exposing the trees to two extreme photoperiods (constant dark or constant light; Fig. 5) to determine whether increasing abundance of CsFT transcripts could be sustained under these conditions. Our results show that under these extreme photoperiods, CsFT transcripts did not increase after $3 \mathrm{~d}$ of exposure to floralinductive temperatures. $C s F T$ transcript abundance under the two extreme photoperiods was not different from pre-induction abundance, whereas $C s F T$ transcript abundance in the control photoperiod $(11 / 13 \mathrm{~h}$ day/night) was $\approx 3.5$ times greater than pre-induction levels. These data suggest that alternation of periods of light and dark is required to sustain $C s F T$ transcript accumulation. Under floral-inductive conditions, the abundance of $C s F T$ transcripts continues to increase for as long as the environmental inductive stimulus is present (Chica and Albrigo, 2013; Nishikawa et al., 2007). Thus, a minimum and maximum photoperiod must exist to sustain floral induction. Furthermore, these results, along from those presented in Figure 1, suggest that although a clock-related component could be involved in the regulation of $C s F T$ expression, light/ dark signals are a major input in the hypothetical mechanism regulating $C s F T$ and consequently the regulation of $C s F T$ might not be a circadian process.

Although the role of the citrus FT gene as a potent promoter of flowering seems to be conserved in citrus and arabidopsis, the specific mechanisms regulating its expression likely have evolved to become adapted to different environmental conditions. Citrus flowering has traditionally been considered to be photoperiod-insensitive; however, it is possible that rather than being insensitive to photoperiod, a wider range of photoperiods could be floral-promoting (or floral-allowing) in citrus. In arabidopsis, the sensitivity of flowering to photoperiod is tightly coupled with the circadian clock through the expression of $C O$. To date, there have been no reports regarding functional characterization of a citrus $C O$ homolog; still abundance of CsFT transcripts is different at different times of the day in a process that could be at least partially regulated by signals from the tree's clock. These diurnal changes in the abundance of $C s F T$ transcripts occurred even under non-inductive conditions suggesting that the accumulation of CsFT transcripts should reach a certain level to promote flowering rather than being merely activated. In our experiments, a single night of exposure to floral-inductive temperatures was enough to increase CsFT transcript accumulation 2-fold. However, CsFT transcript abundance was also sensitive to temperature, so the time required to achieve effective floral induction could vary depending on the temperature regime affecting the trees. Further physiological characterization of genes upstream of CsFT (e.g., CO) homologous to those in the light and other floral-promoting pathways in arabidopsis as well as the characterization of CsFT protein synthesis and distribution patterns could be helpful to obtain a clearer picture of the mechanism regulating floral induction in citrus.

\section{Literature Cited}

Abe, M., Y. Kobayashi, S. Yamamoto, Y. Daimon, A. Yamaguchi, Y. Ikeda, H. Ichinoki, M. Notaguchi, K. Goto, and T. Araki. 2005. FD, a bZIP protein mediating signals from the floral pathway integrator FT at the shoot apex. Science 309:1052-1056. 
An, H., C. Roussot, P. Suarez-Lopez, L. Corbesier, C. Vincent, M. Pineiro, S. Hepworth, A. Mouradov, S. Justin, C. Turnbull, and G. Coupland. 2004. Constans acts in the phloem to regulate a systemic signal that induces photoperiodic flowering of arabidopsis. Development 131:3615-3626.

Cassin, J., J. Bourdeuet, A. Fougue, V. Furon, J.P. Gailland, J. Bourdelles, G. Montaguad, and C. Moreuil. 1969. The influence of climate upon the blooming of citrus in tropical areas. Proc. First Intl. Citrus Symp. 1:315-323.

Chica, E.J. and L.G. Albrigo. 2013. Expression of flower promoting genes in sweet orange during floral inductive water deficits. J. Amer. Soc. Hort. Sci. 138:88-94.

Chomczynski, P. and N. Sacchi. 1987. Single-step method of RNA isolation by acid guanidinium thiocyanate-phenol-chloroform extraction. Anal. Biochem. 162:156-159.

Corbesier, L., I. Gadisseur, G. Silvestre, A. Jacqmard, and G. Bernier. 1996. Design in Arabidopsis thaliana of a synchronous system of floral induction by one long day. Plant J. 9:947-952.

Corbesier, L., C. Vincent, S. Jang, F. Fornara, Q. Fan, I. Searle, A. Giakountis, S. Farrona, L. Gissot, C. Turnbull, and G. Coupland. 2007. FT protein movement contributes to long-distance signaling in floral induction of arabidopsis. Science 316:1030-1033.

Endo, T., T. Shimada, H. Fujii, Y. Kobayashi, T. Araki, and M. Omura. 2005. Ectopic expression of an $F T$ homolog from citrus confers an early flowering phenotype on trifoliate orange (Poncirus trifoliata L. Raf.). Transgenic Res. 14:703-712.

Endo, T., T. Shimada, H. Fujii, F. Nishikawa, A. Sugiyama, M. Nakano, T. Shimizu, Y. Kobayashi, T. Araki, L. Pena, and M. Omura. 2009. Development of a CiFT co-expression system for functional analysis of genes in citrus flowers and fruit. J. Jpn. Soc. Hort. Sci. 78:74-83.

García-Luís, A. and M. Kandušer. 1995. Changes in dormancy and sensitivity to vernalization in axillary buds of Satsuma mandarin examined in vitro during the annual cycle. Ann. Bot. (Lond.) 76:451-455.

Kobayashi, Y., H. Kaya, K. Goto, M. Iwabuchi, and T. Araki. 1999. A pair of related genes with antagonistic roles in mediating flowering signals. Science 286:1960-1962.

Li, Z.-M., J.-Z. Zhang, L. Mei, X.-X. Deng, C.-G. Hu, and J.-L. Yao. 2010. PtSVP, an SVP homolog from trifoliate orange (Poncirus trifoliata L. Raf.), shows seasonal periodicity of meristem determination and affects flower development in transgenic arabidopsis and tobacco plants. Plant Mol. Biol. 74:129-142.

Mathieu, J., N. Warthmann, F. Küttner, and M. Schmid. 2007. Export of FT protein from phloem companion cells is sufficient for floral induction in arabidopsis. Curr. Biol. 17:1055-1060.

Matsuda, N., K. Ikeda, M. Kurosaka, T. Takashina, K. Isuzugawa, T. Endo, and M. Omura. 2009. Early flowering phenotype in transgenic pears (Pyrus communis L.) expressing the CiFT gene. J. Jpn. Soc. Hort. Sci. 78:410-416.

Michaels, S.D., E. Himelblau, S.Y. Kim, F.M. Schomburg, and R.M. Amasino. 2005. Integration of flowering signals in winter-annual arabidopsis. Plant Physiol. 137:149-156.

Moss, G.I. 1969. Influence of temperature and photoperiod on flower induction and inflorescence development in sweet orange (Citrus sinensis L. Osbeck). J. Hort. Res. 44:311-320.

Muñoz Fambuena, N., C. Mesejo, M. Carmen González-Mas, E. Primo-Millo, M. Agustí, and D.J. Iglesias. 2011. Fruit regulates seasonal expression of flowering genes in alternate-bearing Moncada mandarin. Ann. Bot. (Lond.) 108:511-519.

Muñoz Fambuena, N., C. Mesejo, M. González-Mas, D. Iglesias, E. Primo-Millo, and M. Agustí. 2012a. Gibberellic acid reduces flowering intensity in sweet orange [Citrus sinensis (L.) Osbeck] by repressing CiFT gene expression. J. Plant Growth Regul. 31:529-536.

Muñoz Fambuena, N., C. Mesejo, M.C. González-Mas, E. PrimoMillo, M. Agustí, and D.J. Iglesias. 2012b. Fruit load modulates flowering-related gene expression in buds of alternate-bearing Moncada mandarin. Ann. Bot. (Lond.) 110:1109-1118.

Nishikawa, F., T. Endo, T. Shimada, H. Fujii, T. Shimizu, Y. Kobayashi, T. Araki, and M. Omura. 2010. Transcriptional changes in CiFT-introduced transgenic trifoliate orange (Poncirus trifoliata L. Raf.). Tree Physiol. 30:431-439.

Nishikawa, F., T. Endo, T. Shimada, H. Fujii, T. Shimizu, and M. Omura. 2009. Differences in seasonal expression of flowering genes between deciduous trifoliate orange and evergreen Satsuma mandarin. Tree Physiol. 29:921-926.

Nishikawa, F., T. Endo, T. Shimada, H. Fujii, T. Shimizu, M. Omura, and Y. Ikoma. 2007. Increased CiFT abundance in the stem correlates with floral induction by low temperature in Satsuma mandarin (Citrus unshiu Marc.). J. Expt. Bot. 58:3915-3927.

Pfaffl, M.W. 2001. A new mathematical model for relative quantification in real-time RT-PCR. Nucleic Acids Res. 29:e45.

Pillitteri, L.J., C.J. Lovatt, and L.L. Walling. 2004a. Isolation and characterization of a Terminal flower homolog and its correlation with juvenility in citrus. Plant Physiol. 135:1540-1551.

Pillitteri, L.J., C.J. Lovatt, and L.L. Walling. 2004b. Isolation and characterization of Leafy and Apetalal homologues from Citrus sinensis L. Osbeck 'Washington'. J. Amer. Soc. Hort. Sci. 129:846-856.

R Development Core Team. 2011. R: A language and environment for statistical computing. 3 Jan. 2013. <http://www.r-project.org/>.

Ritz, C. and A.N. Spiess. 2008. qpcR: An R package for sigmoidal model selection in quantitative real-time polymerase chain reaction analysis. Bioinformatics 24:1549-1551.

Rodríguez, A., M. Cervera, and L. Peña. 2012. Control of flowering time in citrus through ectopic overexpression of flowering locus $T(F T)$ and apetalal (APl) from sweet orange. Book of abstracts XII Int. Citrus Congress, Valencia, Spain, 18-23 Nov. 2012. p. 80-81 (abstr.). Samach, A., H. Onouchi, S.E. Gold, G.S. Ditta, Z. Schwarz-Sommer, M.F. Yanofsky, and G. Coupland. 2000. Distinct roles of Constans target genes in reproductive development of arabidopsis. Science 288:1613-1616.

Sambrook, J., E. Fritsch, and T. Maniatis. 1989. Molecular cloning, a laboratory manual. 2nd Ed. Cold Spring Harbor Laboratory Press, New York, NY.

Shalom, L., S. Samuels, N. Zur, L. Shlizerman, H. Zemach, M. Weissberg, R. Ophir, E. Blumwald, and A. Sadka. 2012. Alternate bearing in citrus: Changes in the expression of flowering control genes and in global gene expression in on- versus off-crop trees. PLoS One 7:e46930.

Southwick, S.M. and T.L. Davenport. 1986. Characterization of water stress and low temperature effects on flower induction in citrus. Plant Physiol. 81:26-29.

Suárez-Lopez, P., K. Wheatley, F. Robson, H. Onouchi, F. Valverde, and G. Coupland. 2001. CONSTANS mediates between the circadian clock and the control of flowering in arabidopsis. Nature 410:1116-1120.

Tamaki, S., S. Matsuo, H.L. Wong, S. Yokoi, and K. Shimamoto. 2007. Hd3a protein is a mobile flowering signal in rice. Science 316:1033-1036.

Tan, F.-C. and S.M. Swain. 2007. Functional characterization of $A P 3$, SOC1 and WUS homologues from citrus (Citrus sinensis). Physiol. Plant. 131:481-495.

Valiente, J.I. and L.G. Albrigo. 2004. Flower bud induction of sweet orange trees [Citrus sinensis (L.) Osbeck]: Effect of temperature, crop load and bud age. J. Amer. Soc. Hort. Sci. 129:158-164.

Valverde, F., A. Mouradov, W. Soppe, D. Ravenscroft, A. Samach, and G. Coupland. 2004. Photoreceptor regulation of Constans protein in photoperiodic flowering. Science 303:1003-1006.

Wigge, P.A., M.C. Kim, K.E. Jaeger, W. Busch, M. Schmid, J.U. Lohmann, and D. Weigel. 2005. Integration of spatial and temporal information during floral induction in arabidopsis. Science 309:1056-1059.

Yanovsky, M.J. and S.A. Kay. 2002. Molecular basis of seasonal time measurement in arabidopsis. Nature 419:308-312.

Zhang, J.-Z., Z.-M. Li, L. Mei, J.-L. Yao, and C.-G. Hu. 2009. PtFLC homolog from trifoliate orange (Poncirus trifoliata) is regulated by alternative splicing and experiences seasonal fluctuation in expression level. Planta 229:847-859. 